\title{
IMPLEMENTING ISLAMIC PATTERNS IN INTERIOR DESIGN TO ENHANCE THE SPIRITUAL AESTHETIC
}

\author{
DOAA FATIHADDIN, BOB EVES \& MOAMER GASHOOT \\ Faculty of Science \& Technology, Bournemouth University, UK
}

\begin{abstract}
Islamic art works as a platform to deliver the messages of the culture of Islam, which conveys the Islamic identity and values. One of the main features of Islamic art is the depth of meaning behind it, which may contribute to the person's perception of for example spiritual aesthetic. Therefore, this paper discusses the meaning of spiritual aesthetic and its relation to Islamic art, as well as its utilisation in interior design, since interior design has the ability to connect with human behaviour through the interaction of the human and interior environment. A semiotics approach was selected due to its ability to go beyond the meaning, since this study intends to understand how users perceive the aesthetic of physical elements in the interior environment. In this context, this research aims to propose a design strategy that will enhance the spiritual aesthetic within Islamic patterns in interior design. This paper is based on reviewing the current literature as a part of the author's $\mathrm{PhD}$ project.

Keywords: aesthetics, spirituality, aesthetic experience, perceived, semiotics, interior design.
\end{abstract}

\section{INTRODUCTION}

Interior design plays a fundamental role in enhancing the positive energy in space by using the physical elements. The interior design environment is particularly cognisant of both physical and social factors, the physical elements carrying feeling and translating meaning. Meaning is carried out by the physical environment through its use of physical aesthetics, which can be defined as 'cues in the social and physical environment in which people operate, and are therefore likely to call up a sense-making process' [1]. Physical elements such as size, symbols, colours and lighting all combine to confer sense and meaning [2]. Interior designers try to understand the impact of space based on aesthetics and feelings [1].

This research aims to select the Islamic patterns as an interior design element to enhance aesthetic spirituality in an environment, through answering two fundamental questions.

First, what are the preferences of users for Islamic pattern application in interior design that most enhance the spiritual aesthetic? This question has been developed in order to address the interior design application from a user perspective, with particular attention to user preferences regarding the physical elements in the interior design. Second, how does the user perceive the Islamic patterns to enhance the spiritual aesthetic? The purpose of this question is to understand how users perceive Islamic patterns as an interior design physical element, how they are influenced by them and what Islamic patterns mean to them. This understanding will be based on semiotic analysis that will explain the relationship between objects (Islamic patterns) and meaning (the spiritual aesthetic). The importance of the implementation of Islamic patterns emerges from their uniqueness in integrating in-depth meaning and showcasing beauty in the interior environment. The ability of the Islamic patterns to deliver a meaningful message arises from their representation of Islamic morals and principles, which are an essential part of the creation of such patterns. The Islamic patterns not only work as a platform to transport Islamic values, but they also provide a sense of aesthetic and beauty in the interior space. Therefore, it is crucial to examine how the implementation of Islamic patterns in the interior design impacts the spiritual aesthetic, taking into consideration their capability as a means to simultaneously accommodate both meaning and beauty. 


\section{SPIRITUAL AESTHETICS}

Since this study aims to enhance the meaning of the spiritual aesthetics in interior design using Islamic patterns, the researcher has chosen to study spirituality as it relates to aesthetics in connection with art and design.

\subsection{Spirituality}

Although spirituality has been discussed within various fields, including religion, psychology and the workplace, it has not been discussed as an aesthetic phenomenon. Spiritualty comes from the word 'spirit', and is related to anything which might uplift the spirit. As an abstract concept, spirituality is difficult to define.

Spirituality can be used in a less abstract sense to refer to work performance, as is the case in the recently established field of workplace spirituality. Workplace spirituality connects to morality and ethics, meaningful work, and business ethics. Religiously is the relation between the individual and God, and the search for truth and peace [3], [4]. Spiritualty can also refer to the meaning of life, values and beliefs. Some individuals define spiritualty as a space in which they find meaning and peace. Others define it as a subjective experience, unique to each person [5]. It also can be defined as the pursuit of meaning and existence essence. Thus the term spirituality contains various meanings. Although Sheng and Chen (2012) propose that religion is the approach to direct spirituality, spirituality does not belong solely to religion since at times it refers to the meaning of life or to principles or beliefs outside religion [6].

However, although spirituality is related to feelings towards God, values, beliefs or an aesthetics phenomenon, all meanings have an inner or outward motivation depending on the type of spirituality. For example, the inner motivation in religious spirituality could be praying while the outward motivation is meditation [7]. This study will discuss outward forms of motivation such as art and design, while focusing on the spiritual aesthetics.

\subsection{Aesthetics}

The definition of aesthetics has evolved through a series of stages spanning from ancient times to the present day. The word 'aesthetics' is derived from the Greek word aesthesis, referring to perception by the senses and understanding or sensuous knowledge. Aesthetics has existed as a concept since ancient times, but the term 'aesthetics' was not formulated until 1735, when the study of aesthetics was founded by the German philosopher Alexander Baumgarten. Baumgarten defined aesthetics as 'the science that explains how to know things through the senses'. Baumgarten classified aesthetics as a branch of philosophy that cares about the nature of beauty, art, taste, creativity and the appreciation of beauty [8]-[10].

\subsection{Aesthetics and beauty}

Aesthetics and beauty are often used interchangeably, but Baumgarten distinguished the aesthetics by defining it as being concerned with perceptions, perceivers, feelings, emotions and the whole nature of experience, while beauty considered to be related to objects and appearances [10].

Aesthetics is known to evoke emotions and impact behaviour [11]. Eves and Hewitt (2008) write, aesthetics in design is placed under two categories: beauty and perfection; character and expression. These can be applied to design discrete and integrated design media: colour and texture; shape and form, as well as further sensual responses [12]. 
Previously, from Plato to the Age of Enlightenment, beauty had been gauged according to the ideals of the metaphysical world and their traces within nature, making the judgment of beauty entirely objective, so that beauty could be objectively identified in physical objects and was not affected by personal or subjective desires [10].

Half a century after Baumgarten published his definition of aesthetics, philosophers realised that the nature of experience inquiry opened out into issues of subjectivity and identity, with the potential of transforming values and beliefs. This is due to the issue of how experience relates to the question of consciousness and, by consequence, the role of unconscious experience in shaping identity [10]. In 1790, Immanuel Kant prompted a transformation of the judgment of beauty by formulating his Critique of Judgment. Kant claims that the judgment of beauty is basically concerned with feelings and non-conceptual reflection, rather than rational cognition, reformulating judgment of beauty as a subjective exercise rather than an objective one [13].

However, the objective judgment of beauty can be used to explain the aesthetics of Islamic patterns; helping to understand the shape grammar and formal mathematical rules that generates these patterns' beauty and strength. In addition, the subjective judgment of beauty can be applied to understand the aesthetic spirituality of users according to their personal experiences and imagination.

\subsection{Aesthetics and art}

Art is usually associated with beauty, but not all art is beautiful; sometimes art exists without beauty. In Kant's view, art is not a representation of something beautiful, but is rather a beautiful representation of something [13]. Although Hegel writes that art is for a purpose, he rejects the idea of art for art and emphasises that all kinds of art such as music, architecture, drawing and design play important roles beyond a purely aesthetic one. Instead, he wrote, 'art is the sensuous presentation expression of the idea'; the purpose of art is not to create a new or strange idea but to confirm the good and helpful ideas and make them stick in our minds [14].

Baumgarten changed the meaning of the word aesthetics into indulgence of the senses or sensuous delight [15], maintaining that works of art are (primarily) created for the purpose of gratifying the senses. This idea has since been applied to various aspects of the experience of art, such as 'aesthetic judgment, aesthetic attitude, aesthetic understanding, aesthetic emotion, and aesthetic value' [14]. These are all recognised segments of the aesthetic experience and even though one can experience nature or people aesthetically, the expression 'aesthetics' is primarily used in relation to the arts, particularly visual art [9]. Nowadays, aesthetics is commonly viewed as a subdivision of philosophy which deals with art [13].

\subsection{Spiritual aesthetics and art}

The dynamic relation between spiritual aesthetics and art can be observed in any artwork where the artist attempts to convey spiritual feeling [16]. The spiritual aesthetics can be found in different types of art such as artwork, designs, and architecture.

A particularly well-known example of utilising the lighting is Notre Dame du Haut, a Roman Catholic chapel built by Le Corbusier in Ronchamp, France. The asymmetric light admitted by the wall openings emphasises the building's sacred nature. Le Corbusier is famous for his use of the Golden ratio and his insistence that shapes and patterns are not arbitrary [17]. Another example of utilising the light to enhance spiritual feeling can be found 


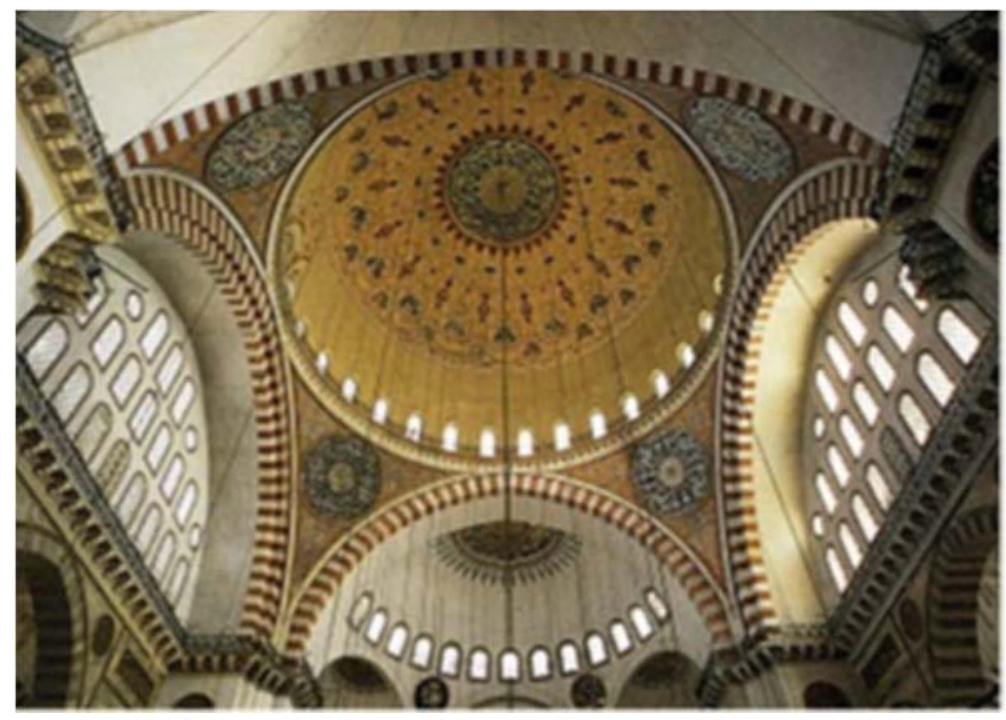

Figure 1: Al-muqarnasat in Suleymaniye mosque [17].

in several Islamic Architectures such as 'Al-muqarnasat', which has been used to trap and spread the light in the worship place (Fig. 1).

\section{ISLAMIC ART}

Islamic art has been studied by western scholars widely in the last two or three decades [18]. Though, Islamic art is not exclusive to Muslim countries; numerous non-Muslim artists has produced Islamic art, at multiple levels of design. That is due to the meaning of the word 'Islam', in Arabic language Islam is 'peace' - peace on various levels; internal peace of the soul, and outer peace with the other [19]. Therefore, Islamic art is broader than religion, bringing peace and tranquillity to the individual viewer and imparting a spiritual feeling to the soul. Islamic art is defined by philosophy rather than material or colour, there is a distinctly unifying principle behind Islamic art which has supplied stable characteristics to this art across time, geography and culture [20].

In addition, there is a distinct philosophy behind Islamic art types. 'Islamic art aids man to be entirely himself; instead of projecting his soul outside of himself. Islamic art as a whole [aims to create] an ambiance which helps man realize his primordial dignity; it, therefore, avoids everything that could be an idol, even in quite a relative and provisional degree; nothing shall stand between a man and the invisible Presence of God' [21]. Accordingly, the exclusion of all anthropomorphic images within worship areas led to the creation of a nonfigural style presented in three distinct forms: the calligraphic or Arabic script style; the Arabesque style, based on curving and branching plant forms; and geometrical patterns (Fig. 2). In many cases, a single work or object features a combination of these three forms. Islamic art is primarily two-dimensional, decorating walls, doors, ceilings and carpets - but it can also be three-dimensional, as in the case of columns and pillars [18], [22], [23].

This study attempts to understand the philosophical characteristics of two-dimensional Islamic geometrical patterns as type of Islamic Art. Sines geometrical patterns greatly associated with sacred places such as mosques, these patterns are instantly recognisable to people of all cultural backgrounds. 


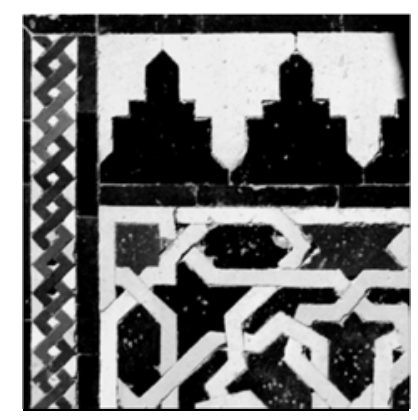

Figure 2: Geometrical patterns in ceramic at Alhambra palace in Spain [19].

\subsection{Islamic geometry, aesthetics and beauty}

The word geometry refers to the science of properties and relations of magnitudes such as points, lines, or surfaces and the way the parts of particular objects fit together. The word 'geometry' comes from two Greek words strung together: geo, meaning earth, and metry, meaning to measure [24]. Islamic art has been inspired by Greek art since the work of Euclid and Pythagoras was translated into Arabic. Pythagoras explains that everything in the universe is defined by mathematics and holds a specific meaning. For example, the world is represented by a cube and a square, fire represented by a triangle and a pyramid and the universe is represented by a dodecahedron [23]. Accordingly, Islamic geometric patterns are symbols and thus evoke meanings, whereas aesthetics is about the knowledge that is formed from our sensory experiences.

Geometry existed in all advanced civilisations, and used in the design of the earliest sacred and traditional sites. Geometry is built according to dimensions that integrate mathematical numbers, constants and ratios, such as the 'golden/sacred mean' [25]. So geometry embodies the sacred by following mathematical proportions and prime roots. On the other hand, mathematical proportions also embody the proportions of beauty; hence Aristotle's claim that 'beauty is to maintain the just measure'. In other words, the mathematical proportions explain the objective judgment of beauty. But this does not mean that judgment of the beauty of Islamic geometry cannot be subjective. Islamic geometries' aesthetics depends on Islamic principles; it is a relationship between Islamic art and Islamic ideology which can be interpreted or perceived according to the individual's experience [24], [26]. Nasr has strongly supported this view, saying:

\section{This art could not perform such a spiritual function if it were not related in the most intimate manner to both the form and content of the Islamic revelation [20].}

An example of Islamic geometry aesthetics inspired by Islamic principles is the achievement of harmony through the synthesis of opposites: dark and light; square and circle which together comprise balance as one of the Islamic principles. The sense of balance is considered as a form of achieving spirituality [16].

Another example of Islamic aesthetics is presented in unity; The Islamic principles have an emphasis on a unity that supplies the same characteristics to the art over vast areas and across different cultures and times [19]. Researchers and scholars agree that the reason behind this unity is the spread of Islamic faith all over the world and the strong impact of Islamic principles on the unity of Islamic art. Unity is the core of Islamic revelation. To embrace Islam one must believe in unification (in Arabic, 'Twhied') and bear witness that there is no 
God but Allah and that Muhammad is His servant/slave and His messenger. Nevertheless, Islam is not limited to worship only, but is a way of life that extends to society, literature and art. The meaning of unity is evident in patterns both ostensibly and implicitly. Ostensibly, by repeating one fundamental unit in the pattern in a coherent way to evoke a sense of unity and harmony. Implicitly, as the meaning of unity is symbolised by the circle, which is the main unit of these patterns and the most common shape in our environment: the universe, the sun and the nucleus that is the beginning of all creatures. It contains a circumference revolving around all constants and one centre, which indicates the oneness of Allah [18], [22], [27]. In geometric patterns, the circle is the base unit for all the patterns which create the six, eight, and ten-pointed stars (Fig. 3). The circle helps the viewer perceive the interlaced composition as a strong unity, which symbolises the one and only God, Allah [22].

Additionally, the combination and repetition are considered as one of the Islamic principles, which can be portrayed in the Islamic geometric pattern. The unit of pattern exhibits properties of symmetry, scalability and movement [28]. The repetition of Islamic worship (the repetition in Muslim's prayers) could be reflected in the geometric pattern.

Hence, the Islamic art aesthetics is from the philosophical characteristics which reinforce and proliferate a shared feeling and expression within the same artistic and spiritual universe [29].

\section{MEANING IN INTERIOR DESIGN}

Butterworth (2000) states that spaces, and places are not only for people's everyday lives; they are embedded with deeper personal and cultural meaning and symbolise personal histories, relationships, people's values and sense of belonging [30]. Interior designers deal with humans' way of interacting with the surrounding environment and the aesthetic components of the interior environment that necessarily reflect the socio-psychological needs of the users. They also contribute to the well-being of humans by analysing the users' needs, values, function, and aesthetics [31].

The study of non-verbal meaning in the environment of interior design is not new, and involves the study of the perceived meaning of and preferences for environments, both of which affect function. Several studies have discussed the non-verbal effect of symbols in interior design; for example, the study of the meaning of symbolism within the social environment is known as environmental semiology (ES) [32]. In addition, Nasar has been studied and measured the non-verbal meaning conveyed by places which carry different emotional responses and that should be appropriate to their function, he asserts that interior

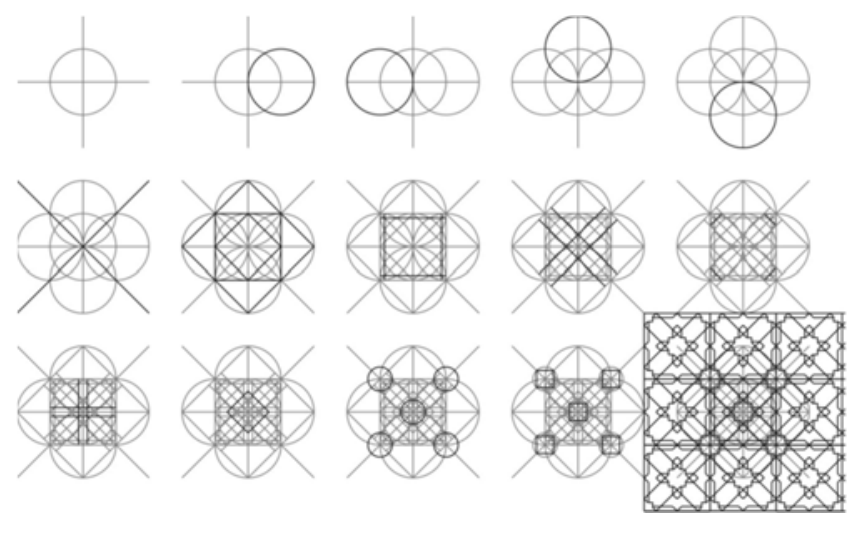

Figure 3: Circle is the base unit for the Islamic patterns [28]. 
environments create an atmosphere which evokes sensations for and interpretations from the occupant [1]. The physical environment could influence human behaviour in two forms: approach and avoidance. Approach behaviour is the positive behaviour that might be directed to a particular place, such as a desire to stay. On the other hand, avoidance behaviour reflects the opposite a desire to avoid the place [11]. For example, the excessive use of ornaments in interior design may cause inconvenience to users and alienate them from the place.

As mentioned above, interior designers try to understand the impact of space based on aesthetics and feelings. On the other hand, social scientists develop the idea of visual quality through the systematic study of environmental preferences and meaning, sometimes in relation to the same attributes that guide designers' instinctual reactions. Both designers and social scientists contribute important knowledge to the field of visual quality, and social scientists frequently draw on designers' ideas in order to construct and test hypotheses. They can also use a combination of both scientific and intuitive knowledge to shape a space's visual quality to achieve client and user goals [1]. It is this combination of approaches which informs the discussion of the theoretical framework elaborated in the following section.

\section{THEORETICAL FRAMEWORK}

The purpose of using a theory in this study is to interpret the perceiving of Islamic art and how this perception can be used to enhance the spiritual aesthetic in interior design. No theory of aesthetics has yet been developed which solely addresses interior design, but an overwhelming body of theories from related fields is available for application to interior design. Existing theories can be adapted from other disciplines; particularly architecture, fine arts and, to a lesser degree, environmental psychology, philosophy and the social sciences, such as gestalt, semiotic, phenomenology, and narrative theories [33]. Consequently, a semiotic approach has been used to understand symbolic meaning as part of the design phenomena [34], [35].

\subsection{Semiotics}

Semiotics is both the science of signs and the study of systems of signs and how they convey and structure meaning [34]. Semiotics can also provide crucial insight into the meanings behind human communication and behaviour [36]. The term semiotics comes from the Greek root sêma which means sign. The pre-history of semiotics extends to the time of Plato, who first pondered the meaning of language, and Aristotle, who considers nouns in Poetics and On Interpretation [37]. However, modern semiotics as we understand it was not developed until the 19th century [36]. Some of the contributors, such as Peirce and Eco, believe semiotics to be the study of signs based on logic, while others, such as Saussure and Barthes, refer to semiotics as semiology, which is the study of sign based on linguistics within society.

The philosopher Charles Sanders Peirce related semiotics to logic, seeking to understand and interpret signs and the relationship between semiotics and perception [38]. His focus was on exploring the structure of meaning within the total human experience. Hence, he adopted the term 'semiosis' to refer to verbal and nonverbal systems of signification and interpretation in the sign system [36]. Peirce believed the universe to be 'perfused with signs if it is not composed exclusively of signs' [39].

Peirce explains meaning through a triadic relationship represented by the 'semiological triangle' (Fig. 4), involving the designatum (the object or concept signified), the sign (the symbol or the signifier used to represent the object) and the interpretant (the one interpreting the sign). Thus, a sign not only stands for something, but it also stands for something to somebody [36], [40]. 


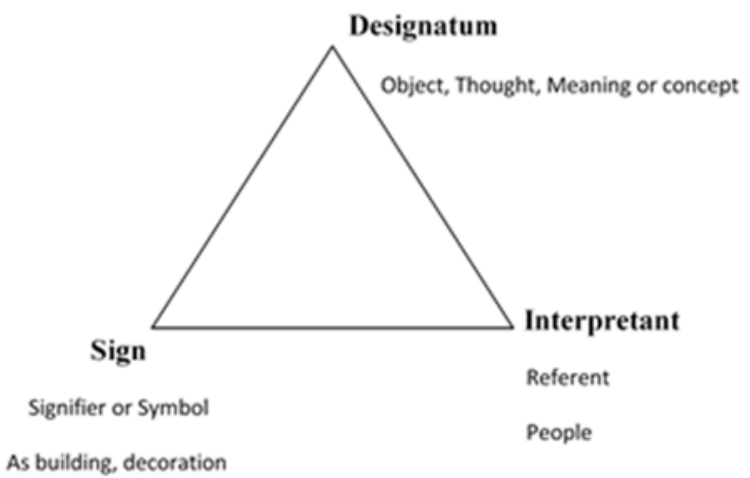

Figure 4: The semiological triangle [43].

Saussure defines the linguistics sign as a 'dyadic' or two-part entity: a 'signifier' and the form or the material aspect of the sign. The 'signifier' is the mental concept that the form represents [37]. It is worth mentioning that Saussure uses the term semiology as opposed to semiotics.

Many scholars from various disciplines have contributed to semiotics, including Jakobson, Morris, Barthes, Percy and Eco. It is not possible to summarise their collective works in this paper. However, Eco's proposed that semiotics is a science that studies every phenomenon from the perspective of signs, and his hypothesis that every cultural phenomenon is a system of signs, are considered to be particularly relevant to this study [41].

\subsubsection{Sign}

Signs and symbols is the first pillar of the semiological triangle, they are important physical elements of the human experience. A sign is anything which represents something else; signs can include sensory information or cultural forms used to create and convey meaning, including language, art, films, religion, and architecture [42]. The terms 'symbol', 'image' and 'sign' are often used interchangeably [2], [36], [43]. Thus, Islamic patterns are the physical elements that are considered as a symbol which can be used in the interior environment.

\subsubsection{Variables and factors affect meaning}

The second pillar of the semiological triangle is meaning. A critical review of various studies of architecture, art and design led the researcher to collect and investigate the physical variables and non-physical variables that affect meaning in interior design. For instance, Nasar evaluates the quality of building exteriors by examining two kinds of aesthetic variables: formal and symbolic. Furthermore, he discusses the relationship between these variables and how this interaction affects the individual's response. Formal aesthetics is the study of the structure, comprised of shape, proportion, colour, and rhythm. On the other hand, symbolic aesthetics is the study of human responses to content of forms and meanings. These content variables reflect the individual's internal representation [44]. Drawing on Jon Lang's examination of symbolic aesthetics within the field of architecture, he proposed that built environments convey symbolic meaning in subtle ways. The correspondence between a building pattern or set of patterns and what is signified has to be learned. He indicates different types of variables which carry symbolic meaning: architectural variables such as 
building configurations, materials, and pigmentation, and non-physical variables such as cultures [43]. Both studies are concerned with architecture and exteriors. While Mazuch and Stephen mention various physical environment design factors relating to interior environments, such as colour, artwork, form, arrangement of furniture, scale and proportion, aroma, sound, texture and materials, natural light and artificial light, and indoor and outdoor plants [45]. Similarly, Bitner lists some of the many physical factors which can enhance users' actions, including lighting, colour, signage, textures, and quality of materials, style of furnishing, layout, wall décor, signs, symbols and artefacts [11]. This study will consider sets of factors when examining the impact of the environment on the spiritual aesthetic in interior design: symbol types on walls, ceilings, floors, and furniture, style, size, material, colour and lighting. These factors will be used to identify the participants' preferences as mentioned above in the research question, by conducting interviews as a method of collecting data and analysing the results in a way to understand the users' perception of the Islamic patterns the third pillar in the semiological triangle (interpretation).

\section{CONCLUSION}

This study has reviewed the current literature in order to establish a fundamental basis from which to conceptualise the research topic. However, there is a lack of research regarding spiritual aesthetics in interior design; most of the existing research examines spirituality from a workplace or psychological perspective. Therefore, this paper has attempted to draw a connection between spirituality and interior design.

In addition, there is a clear deficiency of understanding of the role played by the dimensions of physical environment elements in interior design. Most existing studies choose to focus on single elements such as colour, light and signs. Rather than considering the holistic impact of interior design elements and how these elements enhance specific meanings.

Furthermore, there is a lack of theoretical research that focuses on the users' perception of the interior design. Therefore, this study aims to establish a design strategy for enhancing spiritual aesthetics and to present the physical factors that affect the spiritual aesthetics in interior design by the semiotic approach.

\section{REFERENCES}

[1] Nasar, J., Visual Quality by Design, 1st ed., ASID, 2008.

[2] Alfakhri, D.H., Exploring the impact of hotel interior design through service dominant logic (SDL) and consumer culture theory (CCT) lenses, University of Hull, 2015.

[3] Kamil, N.M., Sulaiman, M., Osman-Gani, A. \& Ahmad, K., Spirituality in the Workplace: The Role of "Taqwa" Towards the Advancement of the Contemporary Organization, Social Science Research Network, 2010.

[4] Issa, T. \& Pick, D., An interpretive mixed-methods analysis of ethics, spirituality and aesthetics in the Australian services sector. Business Ethics: A European Review, 20(1), pp. 45-58, 2011.

[5] Leibrich, J., Making space: Spirituality and mental health. Mental Health, Religion \& Culture, 5(2), pp. 143-162, 2002.

[6] Sheng, C.-W. \& Chen, M.-C., Workplace spirituality scale design - the view of oriental culture. Business and Management Research, 1(4), p. 46, 2012.

[7] Groff, L. \& Smoker, P., Spirituality, religion, culture, and peace: exploring the foundations for inner-outer peace in the twenty-first century. The International Journal of Peace Studies, 1(1), pp. 57-113, 1996. 
[8] Taylor, S.S. \& Hansen, H., Finding form: Looking at the field of organizational aesthetics. Journal of Management Studies, 42(6), pp. 1211-1231, 2005.

[9] Hekkert, P., Design aesthetics: principles of pleasure in design. Psychology Science, 48(2), p. 157, 2006.

[10] Kul-Want, C., Introducing Aesthetics: A Graphic Guide, Icon Books Ltd., 2014.

[11] Bitner, M.J., Servicescapes: The impact of physical surroundings on customers and employees. The Journal of Marketing, pp. 57-71, 1992.

[12] Eves, B. \& Hewitt, J., Semiotics, Design Character Language. Proceedings of E\&PDE 2008, the 10th International Conference on Engineering and Product Design Education, Barcelona, Spain, 04.05.09, 2008.

[13] Breitenbach, A., Beauty in proofs: Kant on aesthetics in mathematics. European Journal of Philosophy, 23(4), pp. 955-977, 2015.

[14] Stejskal, J., The Aesthetic Dimension of Visual Culture, Cambridge Scholars Publishing, 2010.

[15] Goldman, A.H., The broad view of aesthetic experience. The Journal of Aesthetics and Art Criticism, 71(4), pp. 323-333, 2013.

[16] Erzen, J.N., Islamic aesthetics: An alternative way to knowledge. The Journal of Aesthetics and Art Criticism, 65(1), pp. 69-75, 2007.

[17] Ramzy, N., Perceptual dimension of interior daylight in sacred architecture: analytical study of the lighting programsin five sacred buildings of different styles. International Journal of Architecture, Engineering and Construction, 2(4), pp. 219-233, 2013.

[18] Bonner, J., Three traditions of self-similarity in fourteenth and fifteenth century Islamic geometric ornament. Proceedings of Meeting Alhambra, ISAMA-BRIDGES, University of Granada, pp. 1-12, 2003.

[19] Osweis, F.S., Islamic art as an educational tool about the teaching of Islam. Art Education, 55(2), pp. 18-24, 2002.

[20] Nasr, S.H., Islamic Art and Spirituality, State University of New York Press: Albany, 1987.

[21] Burckhardt, T., Perennial values in Islamic art. Al-Abhath, a quarterly of the American University of Beirut (English Section), 20, p. 1, 1967.

[22] Ebru, U.L.U., A Shape Grammar Model to Generate Islamic Geometric Pattern, pp. 290-297, 2009.

[23] Cenani, S. \& Cagdas, G., Shape grammar of geometric Islamic ornaments. Proceedings of the 24th eCAADe, 2006.

[24] Dabbour, L.M., Geometric proportions: The underlying structure of design process for Islamic geometric patterns. Frontiers of Architectural Research, 1(4), pp. 380$391,2012$.

[25] Pennick, N., Sacred Geometry: Symbolism and Purpose in Religious Structures, Turnstone Press, 1980.

[26] Burckhardt, T., Art of Islam: Language and Meaning, World Wisdom, Inc., 2009.

[27] Bier, C., Geometry and the Interpretation of Meaning: Two Monuments in Iran. Bridges: Mathematical Connections in Art, Music, and Science, ed. R. Sarhangi, Winfield KS, pp. 67-78, 2002.

[28] Jowers, I., Prats, M., Eissa, H. \& Lee, J.-H., A Study of Emergence in the Generation of Islamic Geometric Patterns, CAADRIA, 2010.

[29] Shafiq, J., Architectural Elements in Islamic Ornamentation: New Vision in Contemporary Islamic Art, IISTE, 21, 2014.

[30] Butterworth, I., The relationship between the built environment and wellbeing: $a$ literature review, Prepared for the Victorian Health Promotion Foundation, 2000. 
[31] Guerin, D.A. \& Martin, C., The interior design profession's body of knowledge and its relationship to people's health safety, and welfare, University of Minnesota, 2010.

[32] Tan, L., A review of environmental symbology: Origins and contributions toward a theoretical framework. Journal of Interior Design, 36(2), pp. 39-49, 2011.

[33] Loustau, J., A theoretical base for interior design: A review of four approaches from related fields. Journal of Interior Design, 14(1), pp. 3-8, 1988.

[34] Kinross, R., Semiotics and designing. Information Design Journal, 4(3), pp. 190-198, 1984.

[35] Holt, M., Semiotics and design: Towards an aesthetics of the artificial. The Design Journal, 20(sup1), pp. S332-S341, 2017.

[36] Echtner, C.M., The semiotic paradigm: implications for tourism research. Tourism Management, 20(1), pp. 47-57, 1999.

[37] Cobley, P. \& Jansz, L., SemiotiS, 2010.

[38] Mick, D.G. \& Oswald, L.R., The semiotic paradigm on meaning in the marketplace. Handbook of Qualitative Research Methods in Marketing, 31, p. 45, 2006.

[39] Peirce, C.S., Collected papers of Charles Sanders Peirce, 5, Harvard University Press, 1974.

[40] Hawkes, T., Structuralism and Semiotics, Routledge, 2003.

[41] Eco, U., A Theory of Semiotics, Bloomington: Indiana University, 1997.

[42] Berger, A.A., Signs in Contemporary Culture: An Introduction to Semiotics, 1998.

[43] Lang, J., Symbolic aesthetics in architecture: toward a research agenda. Environmental Aesthetics: Theory, Research, and Application, pp. 45-55, 1988

[44] Nasar, J.L., Urban design aesthetics the evaluative qualities of building exteriors. Environment and Behavior, 26(3), pp. 377-401, 1994.

[45] Mazuch, R. \& Stephen, R., Creating healing environments: Humanistic architecture and therapeutic design. Journal of Public Mental Health, 4(4), pp. 48-52, 2005. 